\title{
Ethanol extract of propolis and its constituent caffeic acid phenethyl ester inhibit breast cancer cells proliferation in inflammatory microenvironment by inhibiting TLR4 signal pathway and inducing apoptosis and autophagy
}

\author{
Huasong Chang ${ }^{1+}$, Yuehua Wang ${ }^{1+}$, Xusheng Yin ${ }^{2}$, Xinying Liu ${ }^{2}$ and Hongzhuan Xuan ${ }^{1 *}$
}

\begin{abstract}
Background: Propolis and its major constituent - caffeic acid phenethyl ester (CAPE) have good abilities on antitumor and anti-inflammation. However, little is known about the actions of propolis and CAPE on tumor in inflammatory microenvironment, and inflammatory responses play decisive roles at different stages of tumor development. To understand the effects and mechanisms of ethanol-extracted Chinese propolis (EECP) and its major constituent - CAPE in inflammation-stimulated tumor, we investigated their effects on Toll-like receptor 4 (TLR4) signaling pathway which plays a crucial role in breast cancer MDA-MB-231 cell line.
\end{abstract}

Methods: 80\% confluent breast cancer MDA-MB-231 cells were stimulated with $1 \mu \mathrm{g} / \mathrm{mL}$ lipopolysaccaride (LPS). Then the cells were divided for treatment by CAPE $(25 \mu \mathrm{g} / \mathrm{mL})$ and EECP $(25,50$ and $100 \mu \mathrm{g} / \mathrm{mL})$, respectively. Cell viability, nitric oxide (NO) production and cell migration were measured by sulforhodamine B assay, chemical method and scratch assay. The levels of TLR4, MyD88, IRAK4, TRIF, caspase 3, PARP, LC3B and p62 were investigated through western blotting. The expression of TLR4, LC3B and nuclear factor-KB p65 (NF-KB p65) were tested by immunofluorescence microscopy assay.

Results: Treatment of different concentrations of EECP $(25,50$ and $100 \mu \mathrm{g} / \mathrm{mL})$ and CAPE $(25 \mu \mathrm{g} / \mathrm{mL})$ significantly inhibited LPS-stimulated MDA-MB-231 cell line proliferation, migration and NO production. Furthermore, EECP and CAPE activated caspase 3 and PARP to induce cell apoptosis, and also upregulated LC3-II and decreased p62 level to induce autophagy during the process. TLR4 signaling pathway molecules such as TLR4, MyD88, IRAK4, TRIF and NFKB p65 were all down-regulated after EECP and CAPE treatment in LPS-stimulated MDA-MB-231 cells.

Conclusions: These findings indicated that EECP and its major constituent - CAPE inhibited breast cancer MDA-MB231 cells proliferation in inflammatory microenvironment through activating apoptosis, autophagy and inhibiting TLR4 signaling pathway. EECP and CAPE may hold promising prospects in treating inflammation-induced tumor.

Keywords: Propolis, Caffeic acid phenethyl ester, Anti-inflammatory, Antitumor, Toll like receptor 4

\footnotetext{
* Correspondence: hongzhuanxuan@163.com

${ }^{\dagger}$ Equal contributors

'School of Life Science, Liaocheng University, Liaocheng 252059, China

Full list of author information is available at the end of the article
} 


\section{Background}

Propolis is a resinous material that honey bees collect from various plants, and it has been widely used in folk medicine, food or beverages to improve health and prevent diseases since ancient time for its numerous biological and pharmacological properties, such as antibacterial, antiviral, antitumor and anti-inflammatory activities [1]. Caffeic acid phenethyl ester (CAPE), one of the most important medicinal constituents of propolis, has varieties of important biological activities, including antioxidant, anti-inflammatory, and anti-cancer [2-4].

In recent years, the anti-inflammatory and antitumor actions of propolis and CAPE have been widely documented, and we also found Chinese propolis exhibited significant anti-inflammatory and antitumor effects in vivo and in vitro $[5,6]$, and indentified the bioactive components of Chinese propolis on antitumor activity [7]. However, little is known about the actions of propolis and its major active composition - CAPE on tumor in inflammatory microenvironment. Many researches demonstrate that inflammatory responses play decisive roles at different stages of tumor development, including initiation, promotion, malignant conversion, invasion, and metastasis [8]. Toll-like receptor 4 (TLR4) is well known for its host innate immunity, and recent evidence suggests that TLR4 is over-expressed in the majority of clinical breast cancer and involvement in breast cancer development and progression. Furthermore, the overactivation of TLR4 may cause immune response dysfunction, resulting in tumorigenesis. Thus, reducing expression of TLR4 could inhibit human breast cancer MDAMB-231 cells proliferation and inflammatory cytokines secretion [9].

Inflammatory microenvironment plays an important role in tumor development, but little is known about the actions of propolis and its major active composition CAPE on inflammation-mediated tumor. Thus, the goal of this study was to explore the effects of ethanol extract of Chinese propolis (EECP) and CAPE on lipopolysaccharide (LPS)-stimulated breast cancer MDA-MB-231 cells by testing TLR4 signaling pathway.

In addition, there is a high correlation between autophagy, inflammation and tumor [10-13]. Autophagy is a self-protective mechanism to maintain homestasis by breaking down the intracellular impaired protein or organelles, and it is considered as a two-edge sword having both anti- and pro-tumor functions at different stages of tumor development [14, 15], and more and more new insights strongly indicate that autophagy not only plays its classical role as a housekeeping mechanism, but also can be considered as crucial for induction and modulation of inflammatory reaction [16]. Thus, this study also aimed to evaluate whether propolis and its major constituent - CAPE modulated autophagy in LPS-stimulated breast cancer MDA-MB-231 cells.

\section{Methods \\ Materials}

Dulbecco's Modified Eagle's Medium (DMEM) was purchased from Gibco-BRL (USA). Fetal bovine serum (FBS) was from Hyclone Lab Inc. (USA). LPS (Escherichia coli 0111:B4), sulforhodamine B (SRB), prodium iodide (PI) and CAPE were from Sigma Co. (USA). Primary antibodies against TLR4, NF- $\mathrm{B}$ p65, $\beta$-actin and secondary antibody (horseradish peroxidase) were from Santa Cruz Biotechnology (USA). Primary antibodies against MyD88, TRIF, IRAK4, LC3B, PARP and procaspase 3 were purchased from Cell Signaling Technology (USA). Secondary antibody for immunofluorescence, donkey anti-rabbit IgG Alexa Fluor-488 was purchased from Life Technologies (USA). Nitric oxide (NO) kit was from Nanjing Jiancheng Bioengineering Institute (China). All other reagents were ultrapure grade.

\section{Preparation of propolis ethanol extracts}

Propolis used in the present study was Chinese propolis from Shandong Province of North China and the sample was collected from A.mellifera colonies from the wild, and it was unnecessary to gain permission for this prior to collection. The main plant origin was poplar (Populus sp.). Propolis used in the present experiment was the same as before and the extraction method was as used previously [6]. The ethanol-extracted Chinese propolis (EECP) had a brown color. The prepared propolis was stored under a dry condition at $4{ }^{\circ} \mathrm{C}$.

\section{Total flavonoids measurement and HPLC analysis}

Total flavonoids content of EECP was measured by the method of Chinese Standard (GB/T 20574-2006). The absorbance was read at $415 \mathrm{~nm}$ using an Ultraviolet Spectrophotometry.

HPLC analysis of EECP and CAPE was performed on a Century SIL C18 Eps column $(250 \mathrm{~mm} \times 4.6 \mathrm{~mm}$ I. D., $5 \mu \mathrm{m})$. The mobile phase consisted of methanol and $0.1 \%$ phosphoric acid in gradient elution mode (methanol: $0-8 \mathrm{~min}, 60 \%-70 \%$; $8-30 \mathrm{~min}, 70 \%$; 30-40 $\mathrm{min}$, $70 \%-80 \% ; 40-50 \mathrm{~min})$. The flow rate of the mobile phase was kept at $1.0 \mathrm{~mL} / \mathrm{min}$, and the column temperature was kept at $28^{\circ} \mathrm{C}$. The effluent was monitored by a photodiode array detector (PAD) at $280 \mathrm{~nm}$.

\section{Cell culture}

Breast cancer cell lines MDA-MB-231 was gifted by the Second Military Medical University of China. MDA-MB231 cells was routinely cultured in DMEM supplemented with $10 \%(\mathrm{v} / \mathrm{v})$ FBS and $100 \mathrm{U} / \mathrm{mL}$ of penicillin, 
$100 \mu \mathrm{g} / \mathrm{mL}$ streptomycin at $37{ }^{\circ} \mathrm{C}$ under humidified 95\%-5\% (v/v) air and $\mathrm{CO}_{2}$.

\section{Exposure of MDA-MB-231 cells to EECP}

When the MDA-MB -231 cultures reached $80 \%$ confluence, the cells were divided for treatment: (a) culture in DMEM medium with $10 \%$ FBS with ethanol at $<0.1 \%(v /$ v) (control); (b) the cells were stimulated with $1 \mu \mathrm{g} / \mathrm{mL}$ LPS but cultured in DMEM medium in the presence of $10 \%$ FBS with ethanol at $<0.1 \%(v / v)$ (LPS); and (c) the cells were stimulated with $1 \mu \mathrm{g} / \mathrm{mL}$ LPS but culture in DMEM medium in the presence of $10 \%$ FBS with CAPE $(25 \mu \mathrm{g} / \mathrm{mL})$ and $\operatorname{EECP}(25,50$ and $100 \mu \mathrm{g} / \mathrm{mL})$, respectively. EECP was dissolved in ethanol, with final concentration of ethanol in the culture medium $<0.1 \%(\mathrm{v} / \mathrm{v})$. The morphological changes of cells were observed under a phase contrast microscope (Nikon, Japan).

\section{Cell viability assay}

Cells were seeded at the density of $4 \times 10^{4} / \mathrm{mL}$ into 96well plates and treated with different concentrations of $\operatorname{EECP}(25,50$ and $100 \mu \mathrm{g} / \mathrm{mL})$ and CAPE $(25 \mu \mathrm{g} / \mathrm{mL})$ stimulated with LPS $(1 \mu \mathrm{g} / \mathrm{mL})$. At 24 and $48 \mathrm{~h}$, SRB assay was used to determine cell viability. Briefly, cells were precipitated for $1 \mathrm{~h}$ at $4{ }^{\circ} \mathrm{C}$ with $100 \mu \mathrm{L} 10 \%$ trichloroacetic acid and stained with SRB. The optical density was measured at $492 \mathrm{~nm}$ after reconstitution of the dye in $100 \mu \mathrm{L} 10 \mathrm{mM}$ Tris base. The viability (\%) was expressed as (OD of treated group/OD of LPS group) $\times 100 \%$. The viability of the LPS group was set at $100 \%$.

\section{In vitro scratch assays}

Cells were grown to $80 \%$ confluence in a 24 -well plate, the monolayers were scratched with a plastic tip to create a straight-line cell-free scratch, washed by $1 \times$ PBS to remove floating cell debris, and then incubated in medium in the absence or presence of different concentrations of EECP and CAPE stimulated with LPS $(1 \mu \mathrm{g} / \mathrm{mL})$ for $48 \mathrm{~h}$. The scratch area was marked and photographed in every $12 \mathrm{~h}$. Cell migration into the wound surface was determined under a TE2000S inverted microscope (Nikon, Japan). Migrated cells across the scratched lines were counted by Image-Pro Plus software (USA).

\section{NO production measurement}

The cell medium was collected and centrifuged at $48 \mathrm{~h}$, then dispensed and stored at $-80{ }^{\circ} \mathrm{C}$ until tested. The generation of $\mathrm{NO}$ was assayed by a $\mathrm{NO}$ measurement kit.

\section{Immunofluorescence microscopy assay}

Immunofluorescence assay was performed by the method [17]. MDA-MB-231 cells treated for $48 \mathrm{~h}$ were fixed in $4 \%$ paraformaldehyde $(w / v)$ for $15 \mathrm{~min}$ at room temperature and blocked in 5\% donkey serum $(v / \mathrm{v})$. After adding the primary and second antibodies (FITCIgG), nuclei were counterstained with PI. A laser scanning confocal microscope (Olympus FV1200, Japan) was used for fluorescence detection. Analysis was made by the Image-Pro Plus software (USA). Images are representative of three independent experiments.

\section{Western blotting analysis}

Western blotting assay was performed by a previous method [17]. Cells were washed three times with cold phosphate-buffer saline and lysed in lysis buffer with protease inhibitors at ice. Thirty micrograms of protein were separated by $12 \%$ sodium dodecyl sulfate polyacrylamide gel electrophoresis (SDS-PAGE) and electroblotted to a polyvinylidene difluoride (PVDF) membrane using a semi-dry blotting apparatus (Bio-Rad, USA). The bands are visualized using an enhanced chemiluminesence detection kit (Thermo Electron Corp., USA). $\beta$ actin was used as loading control.

\section{Statistical analysis}

Data are from at least three independent experiments and expressed as means \pm S.E.M. Statistical analysis involved the paired Student $t$ test and ANOVA with SPSS Ins (PASW Statistics 18). Differences were considered statistically significant at $P<0.05$.

\section{Results}

Total flavonoids content of EECP and HPLC assay

Propolis used in the present study was Chinese propolis from Shandong Province, and the main plant origin was poplar (Populus sp.). Total flavonoids content of EECP was $22.68 \%$, and the content of CAPE in EECP was $0.11 \%$ (Fig. 1).

\section{EECP and CAPE decreased LPS-stimulated MDA-MB-231 cells proliferation}

Cell viability was analyzed by SRB assay and the results showed that CAPE and different concentrations of EECP exhibited an obviously inhibitory effect on the proliferation of MDA-MB-231 cells stimulated by LPS in a timeand dose-dependent manner. And the inhibitory effect of CAPE $(25 \mu \mathrm{g} / \mathrm{mL})$ was similar with EECP $50-100 \mu \mathrm{g} / \mathrm{mL}$ $(" P<0.05, "=P<0.01$; Fig. 2).

\section{EECP and CAPE inhibited LPS-stimulated MDA-MB-231 cells migration}

The migration ability of MDA-MB-231 cells was significantly increased upon LPS treatment. CAPE and different concentrations of EECP significantly inhibited cell migration in a dose-dependent manner at 24 and $48 \mathrm{~h}$ $\left({ }^{\prime} P<0.05, "{ }^{* \prime \prime} P<0.01\right.$; Fig. 3$)$. 


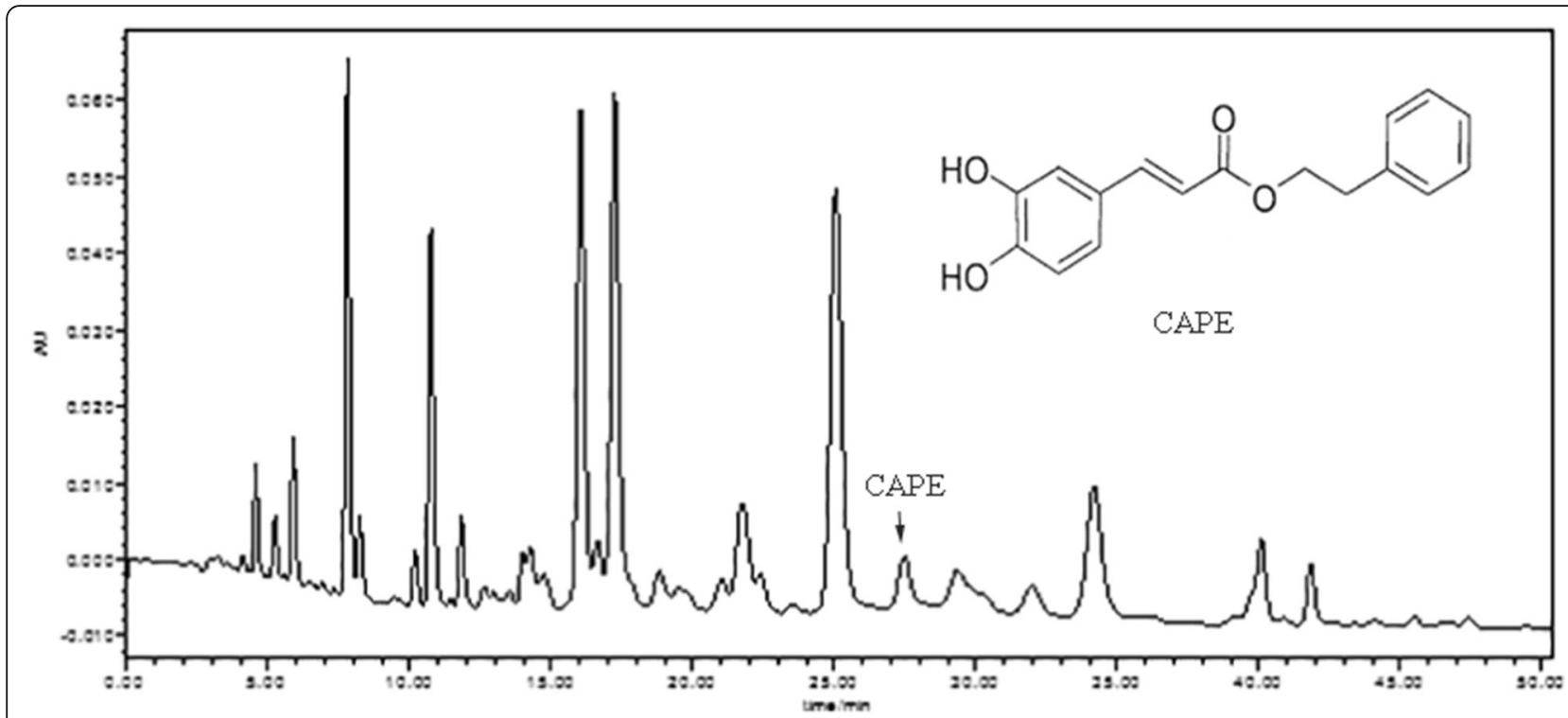

Fig. $1 \mathrm{HPLC}$ chromatograms of ethanol-extracted Chinese propolis (EECP) and caffeic acid phenethyl ester (CAPE)

EECP and CAPE inhibited NO production in LPS-

\section{stimulated MDA-MB-231 cells}

The production of $\mathrm{NO}$ in cell supernate was obviously decreased by CAPE and different concentrations of EECP treatment at 48 h. ( $P<0.05,{ }^{* * *} P<0.01$; Fig. 4).

EECP and CAPE induced apoptosis and autophagy in LPSstimulated MDA-MB-231 cells

We first tested the effects of EECP and CAPE on apoptosis in LPS-stimulated MDA-MB-231 cells. EECP (25$100 \mu \mathrm{g} / \mathrm{mL})$ and CAPE $(25 \mu \mathrm{g} / \mathrm{mL})$ obviously activated caspase 3 and PARP, the executor of apoptosis (Fig. 5a). We then tested whether EECP and CAPE affected autophagy during the process. It is acceptable that the enhancement of the conversion of LC3-I to LC3-II, upregulation of LC3-II expression and the degration of p62 are the credible markers of the autophagosome in mammalian cells $[18,19]$. Distribution of LC3 was detected with an immunostaining assay. When challenged with EECP $(25-100 \mu \mathrm{g} / \mathrm{mL})$ and CAPE $(25 \mu \mathrm{g} / \mathrm{mL})$, cells stained with anti-LC3 antibody showed a distinctively punctuate pattern compared with LPS group (Fig. 5c). Furthermore, EECP and CAPE treatment obviously elevated the level of LC3-II and the ratio of LC3-II/LC3-I. The level of p62 significantly decreased after EECP and CAPE treatment in LPS-stimulated MDA-MB-231 cells at $24 \mathrm{~h}\left(" P<0.05,{ }^{* *} P<0.01\right.$; Fig. 5d).

EECP and CAPE regulated the levels of TLR4, MyD88, IRAK4 and TRIF in LPS-stimulated MDA-MB-231 cells It is reported that TLR4 is over-expressed in the majority of clinical breast cancer and involvement in breast

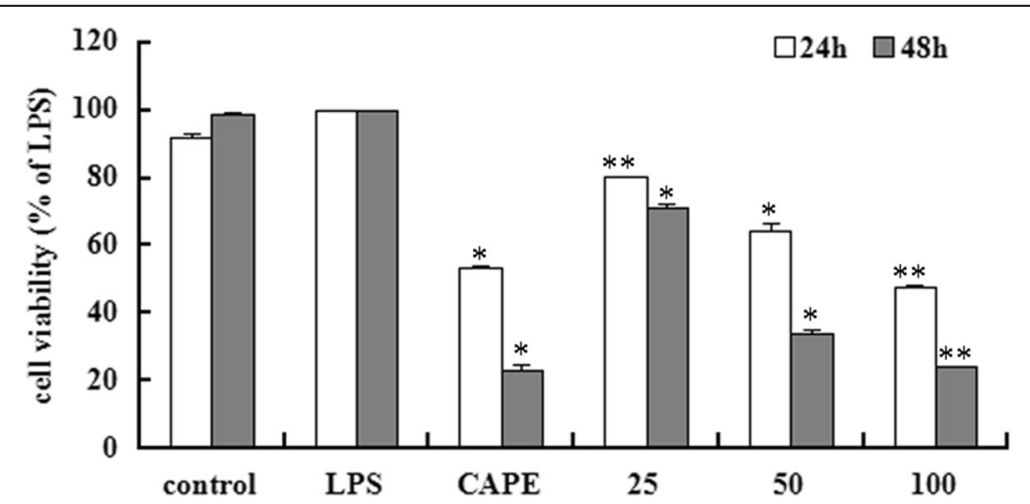

Fig. 2 EECP and CAPE decreased LPS-stimulated MDA-MB-231 cells proliferation at 24 and $48 \mathrm{~h}$. CAPE, cells treated with CAPE at $25 \mu \mathrm{g} / \mathrm{mL} .25$, 50 and $100 \mu \mathrm{g} / \mathrm{mL}$, cells treated with EECP at 25,50 and $100 \mu \mathrm{g} / \mathrm{mL}$, respectively. $\left({ }^{*} P<0.05,{ }^{* *} P<0.01 \mathrm{vs}\right.$ control, $\left.n=3\right)$. Data are means \pm S.E.M 


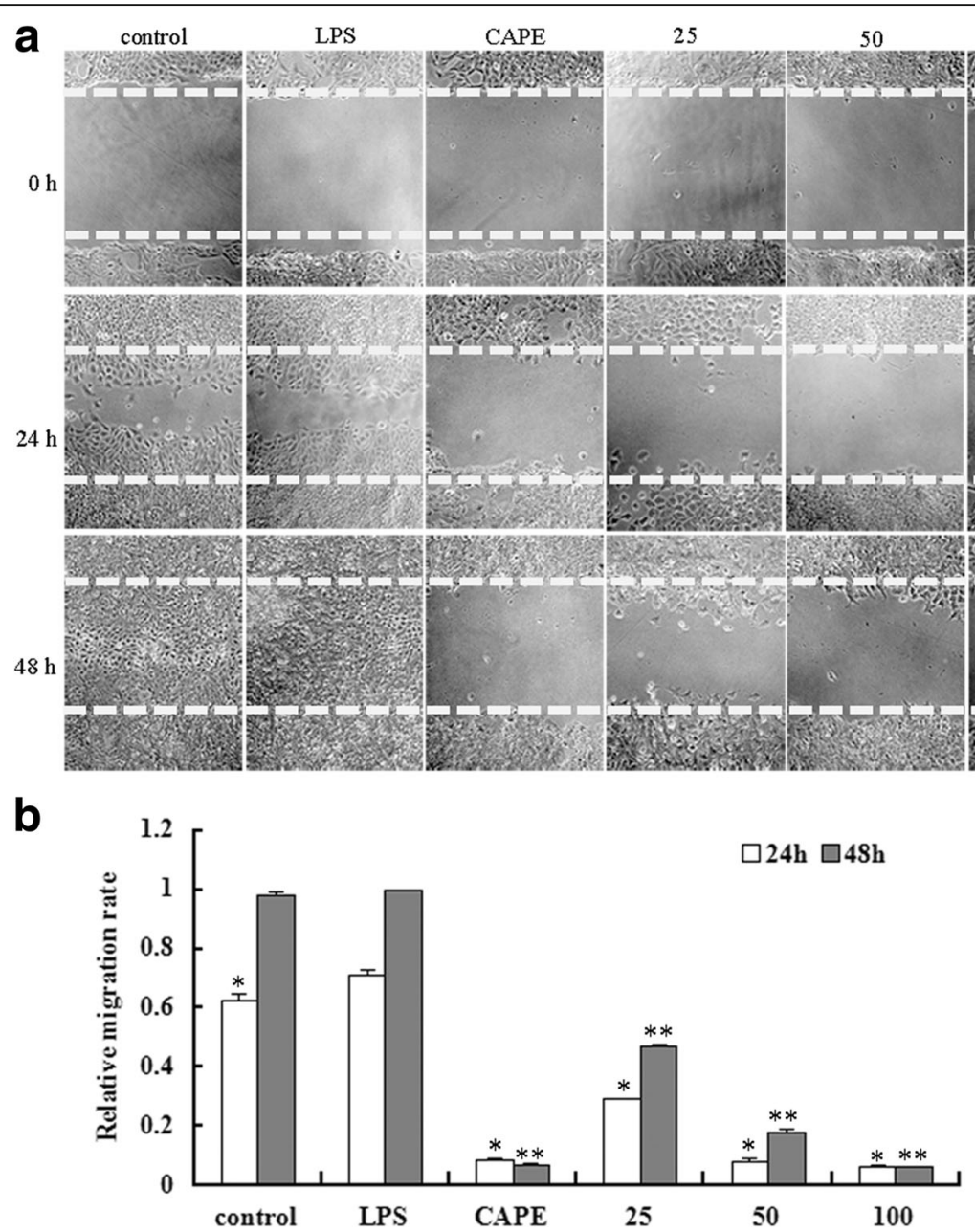

Fig. 3 EECP and CAPE inhibited LPS-stimulated MDA-MB-231 cells migration. a Cell migration micrographs obtained under a phase contrast microscope at 0,24 and $48 \mathrm{~h}(\times 100)$. b Relative levels of cell migration. $\left({ }^{*} P<0.05,{ }^{* *} P<0.01\right.$ vs control, $\left.n=3\right)$. Data are means \pm S.E.M

cancer development and progression. In order to investigate whether EECP and CAPE affected TLR4 signaling pathway, we first tested the level of TLR4 by western blotting and immunofluorescence analysis. Cells treated with EECP and CAPE exhibited lower florescence intensity compared with LPS group (Fig. 6a), and protein level of TLR4 evidently decreased after EECP and CAPE treatment. Then we further tested the downstream signal molecules of TLR4 such as MyD88, IRAK4 and TRIF. The results showed that CAPE and different

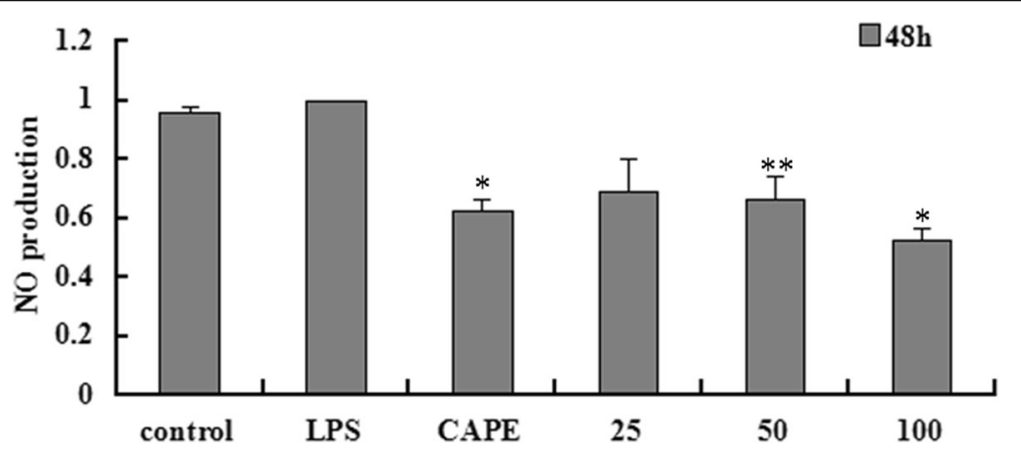

Fig. 4 EECP and CAPE inhibited NO production at 48 h. $\left({ }^{*} P<0.05,{ }^{* *} P<0.01\right.$ vs control, $\left.n=3\right)$. Data are means \pm S.E.M 


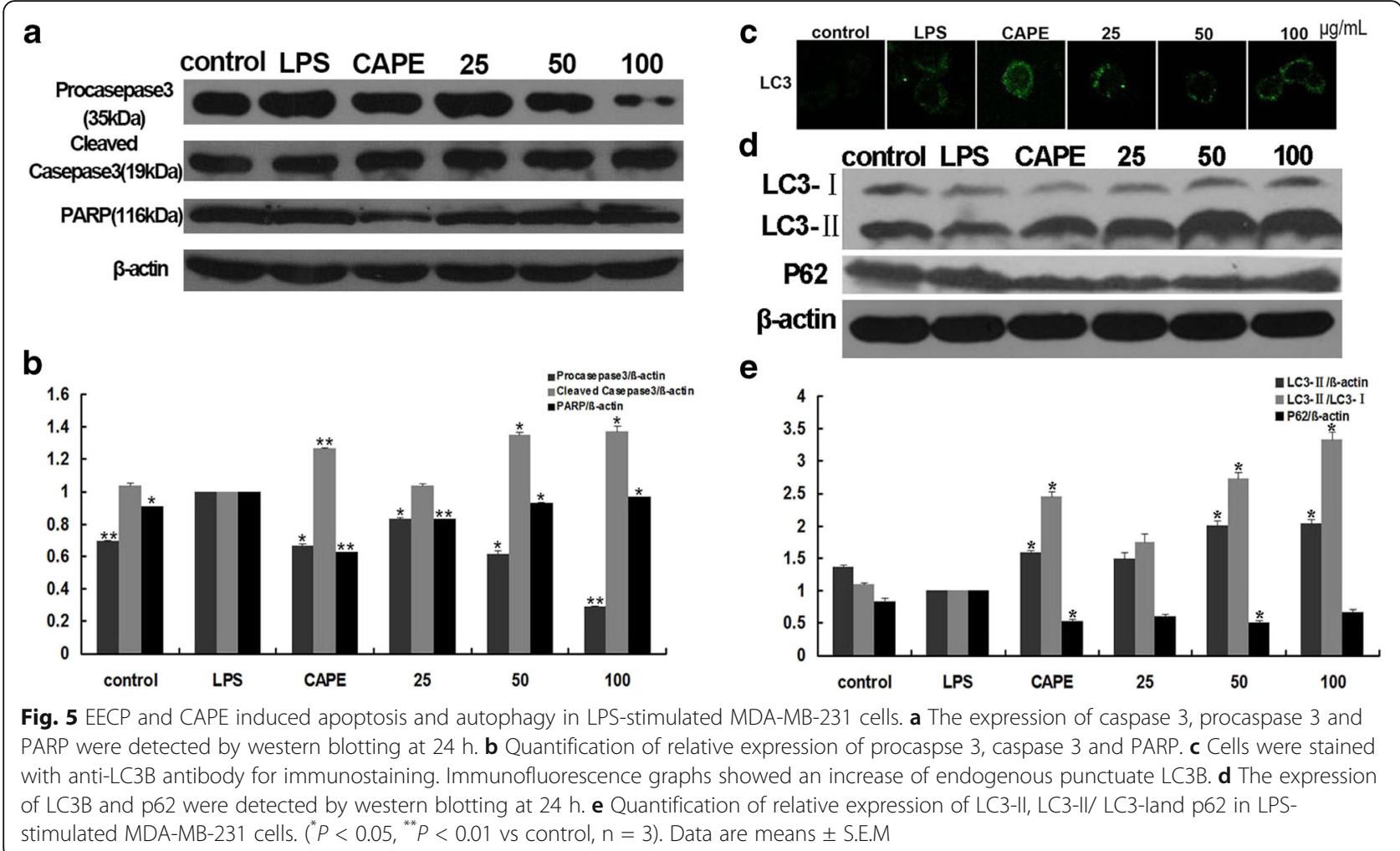

concentrations of EECP significantly decreased the expression of MyD88, IRAK4 and TRIF $\left({ }^{*} P<0.05\right.$, ${ }^{* * *} P<0.01$; Fig. 6b).

EECP and CAPE regulated the levels of NF- KB p65 in LPSstimulated MDA-MB-231 cells

CAPE and different concentrations of EECP significantly down-regulated NF-кB p65 level in a dose-dependent manner by immunofluorescence assay in LPS-stimulated MDA-MB-231 cells. Furthermore, the translocation of NF-kB p65 from cytoplasm to nuclei was also inhibited by CAPE and EECP treatment. $\left(" P<0.05,{ }^{* * *} P<0.01\right.$; Fig. 7).

\section{Discussion}

Propolis is a plant-derived substance collected by honeybees from various sources, and there are more than 600 constituents in propolis, mainly flavonoids and phenolic acids [20]. Our previous study showed propolis had good antitumor effects on different cancer cells such as the human breast cancer cells (MCF-7 and MDA-MB-231), lung cancer cells (A549), human cervical carcinoma cell (HeLa) [6]. And the antitumor bioactive constituents are flavonoids and esters [7]. In addition, propolis exhibit excellent antiinflammatory activities in macrophages (Raw 264.7), ox-LDL stimulated HUVECs and intestinal epithelial Caco-2 cells by modulating key inflammatory mediators of mRNA transcription, inhibiting the production of specific inflammatory cytokines, blocking the activation of nuclear factor NF- $\mathrm{KB}$ and activating AMPK and ERK signaling pathway $[5,21,22]$.

Rudolf Virchow provided the first indication of a possible link between inflammation and cancer in the nineteenth century. And in recent years, numerous studies demonstrated that inflammation plays a critical role in tumorigenesis [23-25]. Accumulating evidence indicated that propolis and CAPE had good abilities in antitumor and anti-inflammatory. Here, we are the first to evaluate the actions of propolis and its major active composition - CAPE on tumor in inflammatory microenvironment, and we found propolis and CAPE induced autophagy and attenuated inflammatory signaling cascade in LPSstimulated human breast cancer MDA-MB-231 cells, then depressed the proliferation of MDA-MB-231 cells.

TLR4 is well known for its host innate immunity. However, recent evidence shows that TLR4 is expressed in a wide variety of tumors such as liver cancer, lung cancer, breast cancer, gastrointestinal cancer, pancreatic cancer. Moreover, there is growing evidence that TLR4 activation appears to act as a double-edged sword in cancers, that is, TLR4 activation has been linked to both cancer inhibition and growth [26]. Yang et al. (2010) reported that ten TLRs were expressed in MDA-MB-231 cells, TLR4 expression was the highest among all the TLRs, and they also demonstrated that knockdown of TLR4 could actively inhibit proliferation and survival of 


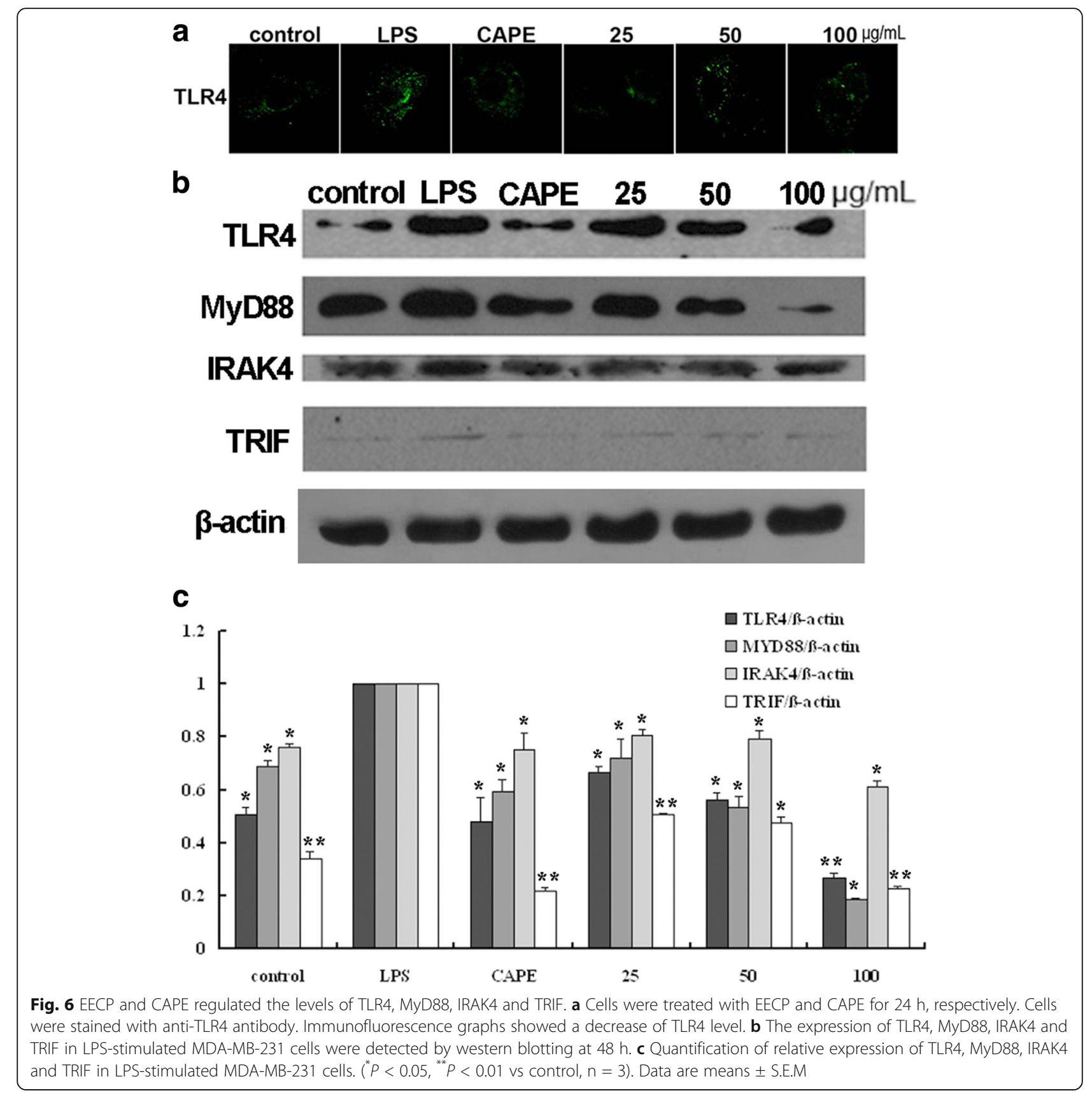

breast cancer cells and RNAi-directed targeting of TLR4 may be a beneficial strategy for breast cancer therapy [27]. In present study, we found EECP and CAPE obviously attenuated TLR4 level in LPS-stimulated MDA-MB-231 cells, which provided novel insights into the potential application of propolis on antitumor in inflammatory microenvironment.

The TLR4 signaling pathway includes MyD88-dependent and MyD88-independent pathways [28]. Both pathways can activate NF-kB to release cytokine. We evaluated the MyD88-dependent signaling pathway molecules such as
MyD88, IRAK4 expressions and TRIF which was involved in MyD88-independent pathway by western blotting assay. Our results suggested that Chinese propolis and its major constituent - CAPE inhibited TLR4 signaling pathway molecules such as TLR4, MyD88, IRAK4, TRIF and NF- kB p65, which might be one of the major causes for Chinese propolis and CAPE to inhibit breast cancer cell proliferation and survive. Based on these results, we deduced that TLR4 signaling pathway might be the target molecule for Chinese propolis and CAPE to inhibit breast cancer cell proliferation in inflammatory-mediated tumor microenvironment. 


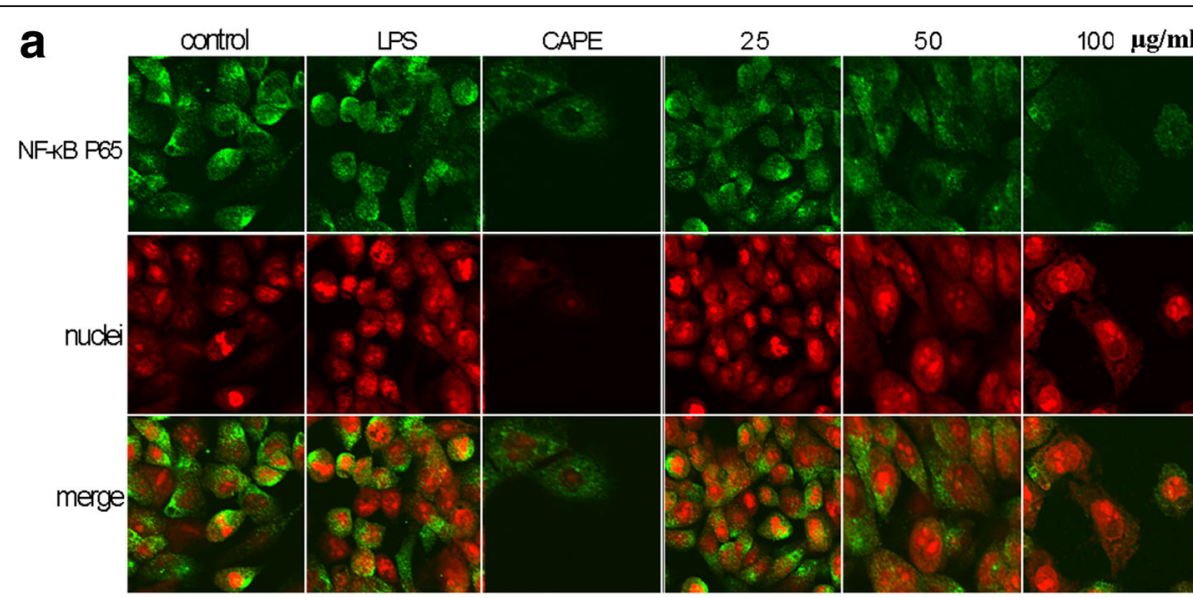

b

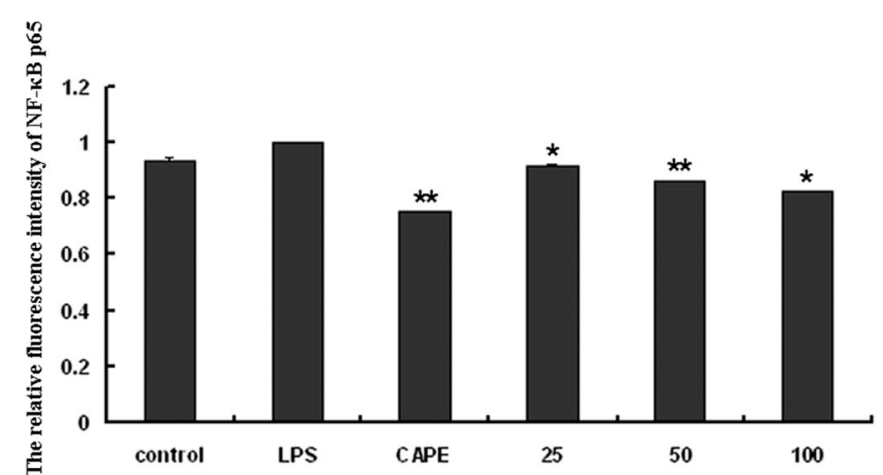

Fig. $7 \mathrm{EECP}$ and CAPE regulated the levels of NF- $k B$ p65. a Fluorescent micrographs obtained at $48 \mathrm{~h}(\times 400)$. b The relative fluorescence intensity of NF-KB p65 in LPS-stimulated MDA-MB-231 cells. ( ${ }^{*} P<0.05,{ }^{* *} P<0.01$ vs control, $\left.n=3\right)$. Data are means \pm S.E.M

Autophagy is an evolutionarily conserved catabolic pathway involved in several physiological processes including cell metabolism, cell survival and host defense [29, 30]. More and more new insights strongly indicate that autophagy also can modulate host defense. Despite the increasing knowledge about the role of autophagy in modulation of inflammation, little is known about the involvement of the autophagy-related SQSTM1-like receptors for the modulation of inflammation [13]. Here we found that Chinese propolis and its major active constituent - CAPE promoted autophagy and inhibited TLR4 signaling pathway to prevent LPS-stimulated breast cancer MDA-MB-231 cells proliferation although the crosstalk between autophagy and inflammation was not known.

Apoptosis was another major cause for Chinese propolis and CAPE to inhibit LPS-stimulated MDA-MB-231 cells survival. We and other researchers all reported that propolis could induce cancer cells apoptosis $[6,31]$. Here we also found that Chinese propolis and CAPE activated caspase 3- the executor of apoptosis in LPS-stimulated breast cancer cells, which might be induced by activating autophagy and depressing TLR4 signaling pathway.

$\mathrm{NO}$, a physiological signaling molecule, is involved in many cellular functions, including cell proliferation, survival and death. A recent study suggested that LPS/ TLR4-induced signaling cascades leads to inducible nitric oxide synthase (iNOS) induction, and inhibition of iNOS might be as a novel effective target therapy against triplenegative breast cancer [32]. In present study, we found Chinese propolis and CAPE obviously inhibited the production of NO, which might inhibit MDA-MB-231 cells survival.

\section{Conclusion}

Based on our finding, propolis and its major component - CAPE could inhibit the proliferation and migration of the TLR4 positive breast cancer MDA-MB-231 cell line in inflammatory microenvironment by activation of apoptosis, autophagy and inhibition of TLR4 signaling pathway. These results provided new insights into the molecular mechanisms underlying the beneficial effects of propolis and CAPE on antitumor in inflammatory microenvironment. However, there are still many problems to be further studied. For example, the crosstalk between autophagy and TLR4 signaling pathway, and the effects of propolis and its major constituents on specific inflammatory cytokines secretion in inflammationmediated tumor are still not known. 


\section{Abbreviations}

CAPE: Caffeic acid phenethyl ester; EECP: Ethanol extract of Chinese propolis; FBS: Fetal bovine serum; iNOS: inducible nitric oxide synthase; LPS: Lipopolysaccaride; NF-kB p65: Nuclear factor-kB p65; NO: Nitric oxide; PVDF: Polyvinylidene difluoride; SDS-PAGE: Sodium dodecyl sulfate polyacrylamide gel electrophoresis; SRB: Sulforhodamine B; TLR4: Toll-like receptor 4

\section{Acknowledgements}

All authors thank Dr. Chongluo Fu for assistance with data extraction.

\section{Funding}

This work was supported by the grant from the National Natural Science Foundation of China (No.31201860, 31672499), Shandong Province Higher Educational Science and Technology Program (J16LE21), Shandong Province Modern Agricultural Technology System (SDAIT-24-05) and Innovation Fund of Liaocheng University (26312150905).

\section{Availability of data and materials}

Data are all contained within the paper.

\section{Authors' contributions}

$\mathrm{HC}$ and $\mathrm{YW}$ performed the experiments and analysed the data. XY and XL organized the data. HX conceived the study idea, designed the experiments and wrote the manuscript. All authors read and approved the final manuscript.

\section{Ethics approval and consent to participate} N/A

\section{Consent for publication}

Not applicable

\section{Competing interests}

The authors declare that they have no competing interests.

\section{Publisher's Note}

Springer Nature remains neutral with regard to jurisdictional claims in published maps and institutional affiliations.

\section{Author details}

'School of Life Science, Liaocheng University, Liaocheng 252059, China. ${ }^{2}$ Institute of Apiculture and bee product quality inspection of Shandong Province, Taian 271000, China.

Received: 24 April 2017 Accepted: 22 September 2017

Published online: 26 September 2017

\section{References}

1. Bankova V. Chemical diversity of propolis and the problem of standardization. J Ethnopharmacol. 2005;100:114-7.

2. Armutcu F, Akyol S, Ustunsoy S, Turan FF. Therapeutic potential of caffeic acid phenethyl ester and its anti-inflammatory and immunomodulatory effects (Review). Exp Ther Med. 2015;9:1582-8.

3. Omene C, Kalac M, Wu J, Marchi E, Frenkel K, O'Connor OA. Propolis and its Active Component, Caffeic Acid Phenethyl Ester (CAPE), Modulate Breast Cancer Therapeutic Targets via an Epigenetically Mediated Mechanism of Action. J Cancer Sci Ther. 2013:5:334-42.

4. Rzepecka-Stojko A, Kabała-Dzik A, Moździerz A, Kubina R, Wojtyczka RD, Stojko R, Dziedzic A, Jastrzębska-Stojko Z, Jurzak M, Buszman E. Caffeic Acid phenethyl ester and ethanol extract of propolis induce the complementary cytotoxic effect on triple-negative breast cancer cell lines. Molecules. 2015: 20(5):9242-62

5. Wang K, Zhang J, Ping S, Ma Q, Chen, X, Xuan H, Shi J, Zhang C, Hu F: Antiinflammatory effects of ethanol extracts of Chinese propolis and buds from poplar (Populusxcanadensis). J Ethnopharmacol. 2014;155:300-11.

6. Xuan H, Li Z, Yan H, Sang Q, Wang K, He Q, Wang Y, Hu F. Antitumor Activity of Chinese Propolis in Human Breast Cancer MCF-7 and MDA-MB231 Cells. Evid Based Complement Alternat Med. 2014;2014:280120.

7. Xuan H, Wang Y, Li A, Fu C, Wang Y, Peng W. Bioactive Components of Chinese Propolis Water Extract on Antitumor Activity and Quality Control. Evid Based Complement Alternat Med. 2016;2016:9641965.
8. Grivennikov SI, Greten FR, Karin M. Immunity, inflammation, and cancer. Cell. 2010;140:883-99.

9. Zhao Y, Kong X, Li X, Yan S, Yuan C, Hu W, Yang Q. Metadherin mediates lipopolysaccharide-induced migration and invasion of breast cancer cells. PLoS One. 2011;6:e29363.

10. Suman S, Sharma PK, Rai G, Mishra S, Arora D, Gupta P, Shukla Y. Current perspectives of molecular pathways involved in chronic Inflammationmediated breast cancer. Biochem Biophys Res Commun. 2016;472(3):104-409.

11. Kang C, Xu Q, Martin TD, Li MZ, Demaria M, Aron L, Lu T, Yankner BA, Campisi J, Elledge SJ. The DNA damage response induces inflammation and senescence by inhibiting autophagy of GATA4. Science. 2015;349:aaa5612.

12. Mao Y, Cheng J, Yu F, Li H, Guo C, Fan X. Ghrelin Attenuated Lipotoxicity via Autophagy Induction and Nuclear Factor-kappaB Inhibition. Cell Physiol Biochem. 2015;37:563-76.

13. Netea-Maier RT, Plantinga TS, Van De Veerdonk FL, Smit JW, Netea MG. Modulation of inflammation by autophagy: consequences for human disease. Autophagy. 2016;12(2):245-60.

14. Edinger AL, Thompson CB. Defective autophagy leads to cancer. Cancer Cell. 2003:4:422-4.

15. Shintani T, Klionsky DJ. Autophagy in health and disease: a double-edged sword. Science. 2004;306:990-5.

16. Ryter SW, Mizumura K, Choi AM. The impact of autophagy on cell death modalities. Int J Cell Biol. 2014;2014:502676.

17. Wang L, Dong Z, Huang B, Zhao B, Wang H, Zhao J, Kung H, Zhang S, Miao J. Distinct patterns of autophagy evoked by two benzoxazine derivatives in vascular endothelial cells. Autophagy. 2010;6:1115-24.

18. Bjorkoy G, Lamark T, Brech A, Outzen H, Perander M, Overvatn A, Stenmark $H$, Johansen T. p62/SQSTM1 forms protein aggregates degraded by autophagy and has a protective effect on huntingtin-induced cell death J Cell Biol. 2005;171:603-14.

19. Tanida I, Minematsu-Ikeguchi N, Ueno T, Kominami E. Lysosomal turnover, but not a cellular level, of endogenous LC3 is a marker for autophagy. Autophagy. 2005:1:84-91.

20. Huang S, Zhang CP, Wang K, Li GQ, Hu FL. Recent advances in the chemica composition of propolis. Molecules. 2014;19:19610-32.

21. Xuan H, Li Z, Wang J, Wang K, Fu C, Hu FL. Propolis reduces phosphatidylcholine-specific phospholipase $\mathrm{C}$ activity and increases annexin a7 level in oxidized-LDL-stimulated human umbilical vein endothelial cells. Evid Based Complement Alternat Med. 2014;2014:465383.

22. Wang $K$, Jin X, Chen $Y$, Song Z, Jiang X, Hu F, Conlon MA, Topping DL. Polyphenol-rich propolis extracts strengthen intestinal barrier function by activating AMPK and ERK Signaling. Nutrients. 2016:8:272.

23. Karin M. Nuclear factor-kappaB in cancer development and progression. Nature. 2006:441:431-6.

24. Colotta F, Allavena P, Sica A, Garlanda C, Mantovani A. Cancer-related inflammation, the seventh hallmark of cancer: links to genetic instability. Carcinogenesis. 2009;30:1073-81.

25. Joyce JA, Pollard JWL. Microenvironmental regulation of metastasis. Nat Rev Cancer. 2009;9:239-52

26. Mai CW, Kang YB, Pichika MR. Should a Toll-like receptor 4 (TLR-4) agonist or antagonist be designed to treat cancer? TLR-4: its expression and effects in the ten most common cancers. Onco Targets Ther. 2013;6:1573-87.

27. Yang $H$, Zhou $H$, Feng $P$, Zhou X, Wen $H$, Xie X, Shen H, Zhu X. Reduced expression of Toll-like receptor 4 inhibits human breast cancer cells proliferation and inflammatory cytokines secretion. J Exp Clin Cancer Res. 2010;29:92.

28. Lu YC, Yeh WC, Ohashi PS. LPS/TLR4 signal transduction pathway. Cytokine. 2008:42:145-51.

29. Kuballa P, Nolte WM, Castoreno AB, Xavier RJ. Autophagy and the immune system. Annu Rev Immunol. 2012:30:611-46.

30. Tey SK, Khanna R. Host immune system strikes back: autophagy-mediated antigen presentation bypasses viral blockade of the classic MHC class I processing pathway. Autophagy. 1839-1841;2012:8.

31. Frozza CO, Ribeiro Tda S, Gambato G, Menti C, Moura S, Pinto PM, Staats CC, Padilha FF, Begnini KR, de Leon PM. Proteomic analysis identifies differentially expressed proteins after red propolis treatment in Hep-2 cells. Food Chem Toxicol. 2014:63:195-204

32. Granados-Principal S, Liu Y, Guevara ML, Blanco E, Choi DS, Qian W, Patel T, Rodriguez AA, Cusimano J, Weiss HL. Inhibition of iNOS as a novel effective targeted therapy against triple-negative breast cancer. Breast Cancer Res. 2015;17:25. 